\title{
Gastric Hyperplastic Polyps Associated with Proton Pump Inhibitor Use in a Case without a History of Helicobacter pylori Infection
}

\author{
Shuichi Miyamoto ${ }^{1}$, Mototsugu Kato ${ }^{2}$, Kana Matsuda ${ }^{1}$, Satoshi Abiko ${ }^{1}$, Momoko Tsuda ${ }^{1}$, \\ Takeshi Mizushima ${ }^{1}$, Keiko Yamamoto ${ }^{1}$, Shoko Ono ${ }^{3}$, Takahiko Kudo ${ }^{1}$, Yuichi Shimizu ${ }^{3}$, \\ Kanako C. Hatanaka ${ }^{4}$, Izumi Tsunematsu ${ }^{5}$ and Naoya Sakamoto ${ }^{1}$
}

\begin{abstract}
A 56-year-old man with gastroesophageal reflux disease (GERD) was referred to our hospital. Esophagogastroduodenoscopy (EGD) revealed no evidence of any polypoid lesions in the stomach, and the patient had no history of Helicobacter pylori infection. He received omeprazole $(20 \mathrm{mg})$ once daily for the GERD. EGD was performed at 1 year after the start of omeprazole administration, and this time, gastric hyperplastic polyps (GHPs) were detected. The GHPs increased in size as the omeprazole treatment continued, but they markedly decreased in size following omeprazole discontinuation. Thus, the administration of proton pump inhibitors may be a risk factor for the development of GHP independent of $H$. pylori infection.
\end{abstract}

Key words: gastric hyperplastic polyp, Helicobacter pylori, proton pump inhibitor, gastrin receptor, gastrin

(Intern Med 56: 1825-1829, 2017)

(DOI: 10.2169/internalmedicine.56.8040)

\section{Introduction}

Acid-related disorders, such as gastric or duodenal ulcers and gastroesophageal reflux disease (GERD), are effectively treated by suppressing gastric acid with proton pump inhibitors (PPIs). PPIs are widely used, with an increasing number of users (1) and an increasing rate of long-term use $(1,2)$. Adverse effects related to long-term use of PPIs, such as fractures (3), enteric infections (4), and development of gastric polyps (5), have been reported. PPIs are also associated with pathological changes, such as parietal cell protrusions and oxyntic gland dilations (6); meanwhile, their long-term use is associated with the development of fundic gland polyps (FGPs) resulting from a trophic effect on parietal cells $(5,7,8)$.

Gastric hyperplastic polyps (GHPs) are the most common type of polypoid lesions in addition to FGPs $(9,10)$. The development of GHPs is strongly associated with Helicobacter pylori infection $(11,12)$, with the majority disappearing or decreasing in size after the eradication of $H$. pylori $(12,13)$. The development of GHPs is very rare in the normal gastric mucosa without a history of $H$. pylori infection $(14,15)$.

The long-term use of PPIs has also been reported to be strongly associated with the development of FGPs (8). A few cases of GHPs associated with PPI use have been reported, but the association between GHPs and PPI use remains unclear $(16,17)$. We herein report a patient without a history of $H$. pylori infection had GHPs associated with PPI use; in addition, we describe the pathological evaluation of the entire GHP tissue following endoscopic mucosal resection.

\footnotetext{
${ }^{1}$ Department of Gastroenterology and Hepatology, Hokkaido University Graduate School of Medicine, Japan, ${ }^{2}$ National Hospital Organization Hakodate Hospital, Japan, ${ }^{3}$ Division of Endoscopy, Hokkaido University Hospital, Japan, ${ }^{4}$ Department of Surgical Pathology, Hokkaido University Hospital, Japan and ${ }^{5}$ Department of Internal Medicine, Toei Hospital, Japan Received for publication July 22, 2016; Accepted for publication January 12, 2017 Correspondence to Dr. Mototsugu Kato, mkato1957@gmail.com
} 
(A)

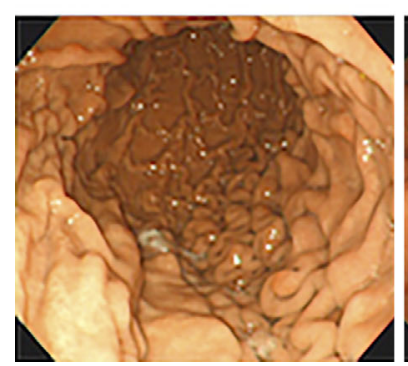

(B)

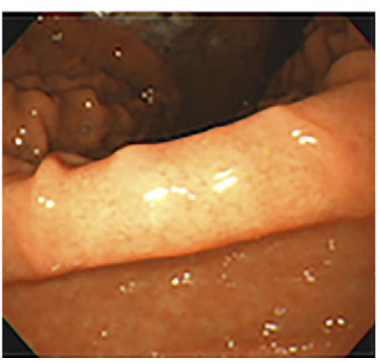

(C)

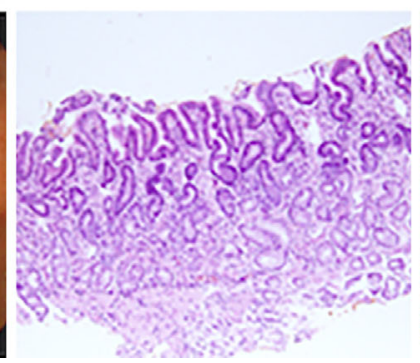

(D)

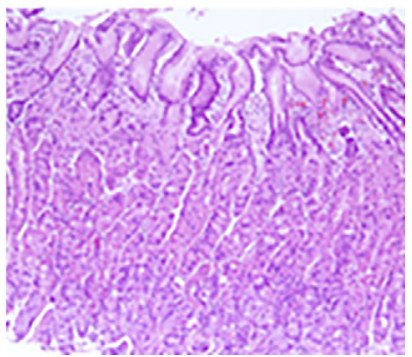

Figure 1. (A) Initial endoscopic image. Note the presence of a regular arrangement of collecting venules (RAC) and no atrophic changes in the gastric body. (B) Initial endoscopic image. Note the presence of RAC and no atrophic changes in the gastric angle. (C) Histology of a biopsy specimen from the gastric antrum showed no atrophic change, no metaplasia, and no infiltration of neutrophils. [Hematoxylin and Eosin (H\&E) staining, original magnification, 100×]. (D) Histology of a biopsy specimen from the gastric body showed no atrophic change, no metaplasia, and no infiltration of neutrophils. (H\&E staining, original magnification, 100x).

\section{(A)}

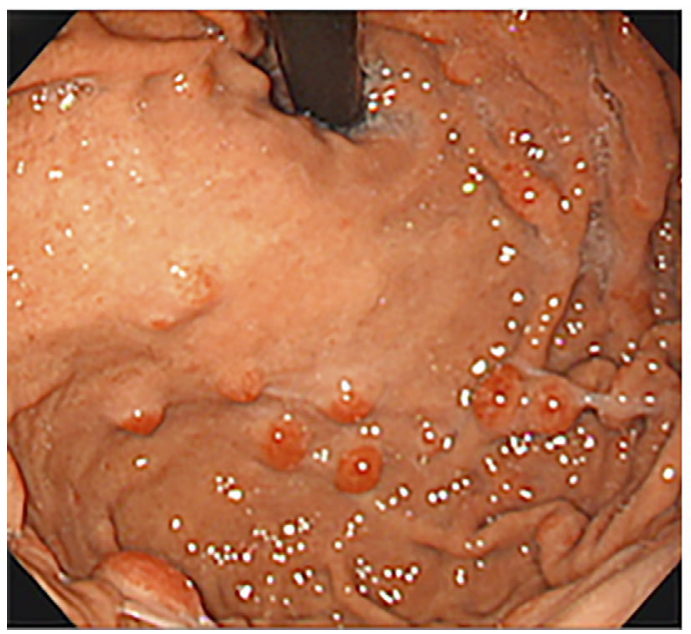

(B)

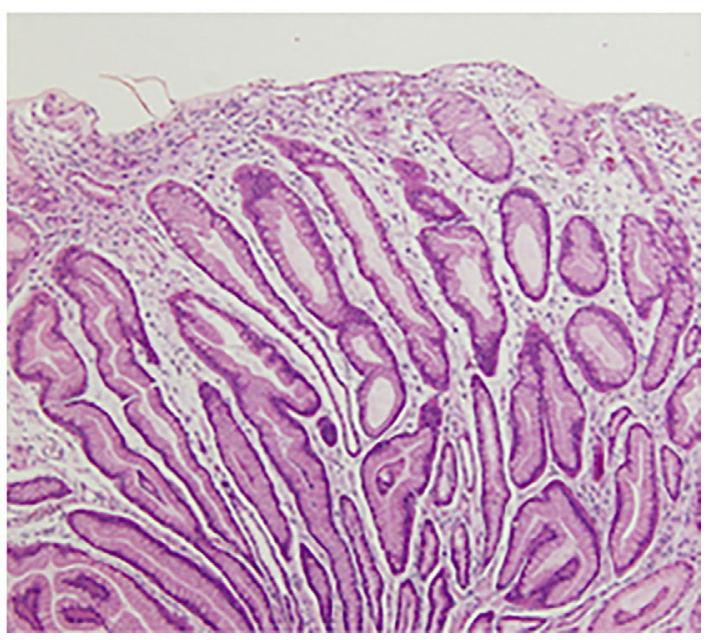

Figure 2. (A) Endoscopic image after 1 year of treatment with omeprazole, a proton pump inhibitor. Note the presence of gastric hyperplastic polyps in the gastric body. (B) Histology of a biopsy specimen from a gastric hyperplastic polyp showed elongation and the branching of foveolae. (Hematoxylin and Eosin staining, original magnification, 100x).

\section{Case Report}

A 56-year-old man with GERD was referred to Hokkaido University Hospital. Initial esophagogastroduodenoscopy (EGD) showed no evidence of any polypoid lesions. The endoscopic findings showed no infection with $H$. pylori according to the Kyoto classification (15), i.e., regular arrangement of collecting venules (RAC) in the gastric angle and no atrophic changes (Fig. 1A and B). The patient was negative for all $H$. pylori tests, including the ${ }^{13} \mathrm{C}$-urea breath test (Otsuka Pharmaceutical, Tokyo, Japan), the rapid urease test (Otsuka Pharmaceutical), the H. pylori IgG E-plate (Eiken Chemical, Tokyo, Japan), culture and histological examinations of gastric biopsy tissues of the antrum and body areas.
In addition, he had no history of $H$. pylori eradication. The histological assessment of biopsy tissues showed no atrophic change, no intestinal metaplasia and no infiltration of neutrophils (Fig. 1C and D). Therefore, the patient was deemed to have no history of $H$. pylori infection. The patient received omeprazole $(20 \mathrm{mg})$ once daily for GERD. Small polyps in the gastric body were endoscopically found 1 year after the initial omeprazole administration (Fig. 2A), and a biopsy led to the pathological diagnosis of GHPs (Fig. 2B). GHPs increased in size (Fig. 3) with the continual administration of omeprazole, and the serum gastrin level (SGL) after fasting increased to $529 \mathrm{pg} / \mathrm{mL}$. At the 4-year followup, a large GHP was endoscopically removed. A pathological examination of the GHP tissue showed elongation, branching, twisting, and dilation of foveolae 


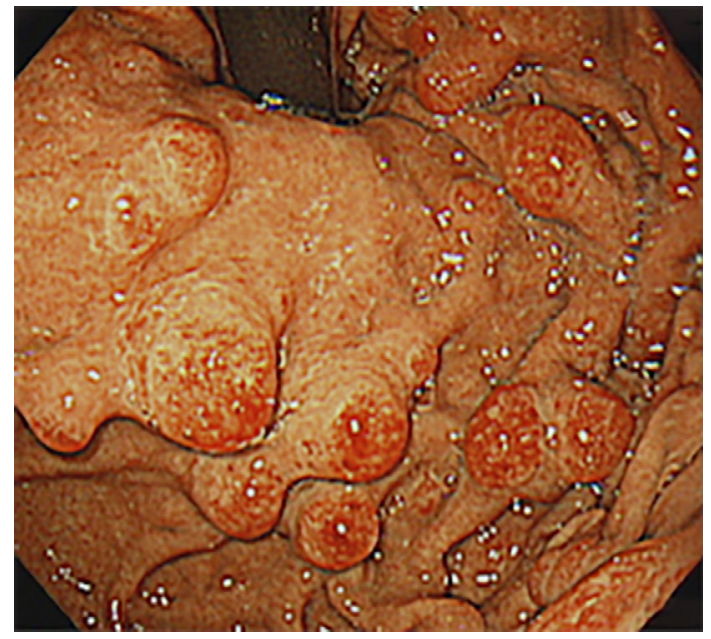

Figure 3. Endoscopic image after 4 years of treatment with a proton pump inhibitor. Note the increase in the size of the gastric hyperplastic polyps.

(Fig. 4A and B), and immunohistochemical staining revealed the expression of gastrin receptor (GR) using the polyclonal antibody OK-524 (1:100, Immuno-Biological Laboratories Corporation, Japan) (18) in the focal foveolar epithelium (Fig. 4C). Repeated EGD performed 1 year after omeprazole was discontinued showed that nearly all GHPs had markedly decreased in size (Fig. 5). SGL after fasting also returned to its normal value $(165 \mathrm{pg} / \mathrm{mL})$.

\section{Discussion}

In a patient without a history of $H$. pylori infection, GHPs occurred, and increased in size with continued PPI use, and then markedly decreased following the discontinuation of PPI administration alone. We confirmed the expression of GR in the focal foveolar epithelium of the GHP.

GHPs are the most common type of gastric polyps which are reported in $6.35 \%$ of patients undergoing EGD and comprising approximately $17 \%$ of all gastric polyps (19). H. pylori infection is considered to increase the risk of GHP development (20), with several reports confirming the disappearance of GHPs following $H$. pylori eradication $(12,20,21)$. However, our patient had no history of $H$. pylori infection, and GHPs markedly decreased following the discontinuation of PPI administration alone.

In general, GHPs with $H$. pylori infection are histologically characterized by the dilation and elongation of the foveolar epithelium. In addition, the stroma of GHPs shows edema, myofibroblasts, and mixed inflammatory cells (22). In this case, the dilation and elongation of the foveolar epithelium and vascularity of the stroma were observed as well as GHPs with H. pylori infection, however, the edema and a number of inflammatory cells of stroma were fewer than the number of GHPs with $H$. pylori infection.

Ito et al. demonstrated that the polyclonal antibody OK524 recognizes human GR and confirmed the expression of GR in parietal cells, enterochromaffin-like cells, and foveo- lar epithelium with intestinal metaplasia (18). Takamura et al. demonstrated a significantly high expression of GR in the foveolar epithelium of the regenerating injured mucosa infected with $H$. pylori (23). Although this patient had no history of $H$. pylori infection, immunohistochemical staining of GHP using OK-524 revealed an expression of GR in the focal foveolar epithelium of GHP (Fig. 4C). We confirmed that immunohistochemical staining with OK-524 revealed no expression of GR in the foveolar epithelium of the gastric antrum mucosa as a negative control. In addition, we performed immunohistochemical staining with OK-524 of parietal cells as a positive control (Fig. 4D-2) and immunohistochemical staining with Anti-Proton Pump (H, K-ATPase $\alpha$ subunit) $\mathrm{mAb}$ (Medical \& Biological Laboratories, Japan) of parietal cells (Fig. 4D-3).

Gastrin is a multifunctional polypeptide hormone that stimulates gastric acid secretion and promotes cell growth $(24,25)$. It stimulates the expression of regenerating islet-derived $1 \alpha(\mathrm{REG} 1 \alpha)$ protein and connective tissue growth factor (CTGF) in the gastric epithelial cells. REG1 $\alpha$ has a trophic effect on gastric mucosal cells and CTGF expression involved in remodeling of the gastric epithelium (26-29). SGL is usually elevated in patients taking PPIs because the feedback inhibition of gastrin release is diminished (30). Therefore, gastric foveolar epithelium expressing GR may lead to GHP development in response to gastrin stimulation.

Hongo et al. demonstrated the presence of GHPs to be related to the $H$. pylori-positive status in patients undergoing long-term PPI therapy (5). Few cases of GHPs associated with PPI use have so far been reported, but the association between GHPs and PPI use remains unclear $(16,17)$. These reports did not investigate whether the patient had any history of $H$. pylori infection. In this case, the patient had no history of $H$. pylori infection. Therefore, the development of GHPs was associated with PPI use and it was not affected by $H$. pylori infection. In addition, we documented not only the initial progression, but also the subsequent regression of the GHPs. In conclusion, this case suggested that PPI use may increase the risk of GHP development in patients without a history of $H$. pylori infection.

\section{Author's disclosure of potential Conflicts of Interest (COI).} Mototsugu Kato: Honoraria, Eisai Co., Ltd., Daiichi Sankyo Co., Ltd., and AstraZeneca K.K.; Scholarship grants, Eisai Co., Ltd., Takeda Pharmaceutical Co., Ltd., Daiichi Sankyo Co., Ltd., AstraZeneca K.K. and Astellas Pharma Inc. Y. Naoya Sakamoto: Honoraria, Bristol-Myers Squibb and Janssen Pharmaceutical K. K.; Research funding, Chugai Pharmaceutical Co., Ltd. and Bristol-Myers Squibb.

\section{Acknowledgement}

I am indebted to Professor Dr. H. Kawakami of the Department of Gastroenterology of Miyazaki University for editing and reviewing the manuscript. 
(A)

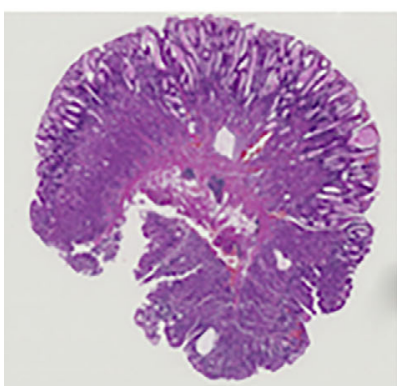

(B)

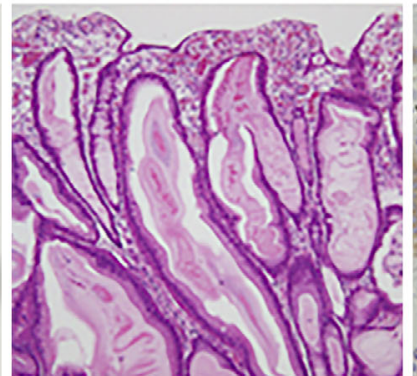

(C)

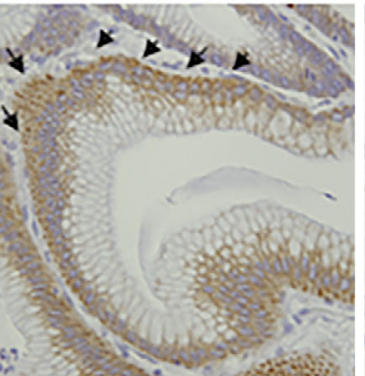

(D)

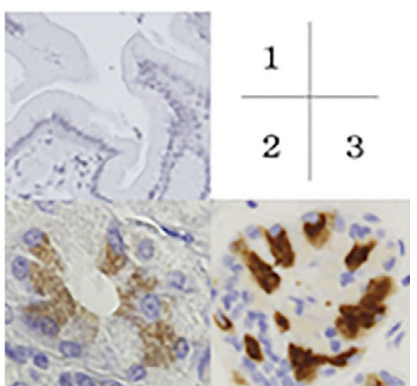

Figure 4. Pathological findings of a gastric hyperplastic polyp obtained during endoscopic mucosal resection. (A) Histology of an endoscopic mucosal resection specimen from a large gastric hyperplastic polyp. [Hematoxylin and Eosin $(H \& E)$ staining; original magnification, $\times 2$ ]. (B) Histology of the foveolar mucosa showing elongation and branching of the foveolae. (H\&E staining; original magnification, $\times 100)$. (C) Immunohistochemical staining with $\mathrm{OK}-524$ revealed the focal expression of gastrin receptor (GR) in the foveolar epithelium. (Original magnification, $\times 400)$. (D) 1: Immunohistochemical staining with OK-524 revealed no expression of GR in the foveolar epithelium of the gastric antrum mucosa as a negative control. 2: Immunohistochemical staining with OK-524 of parietal cells as a positive control. 3: Immunohistochemical staining with Anti-Proton Pump (H, K-ATPase $\alpha$ subunit) mAb of parietal cells.

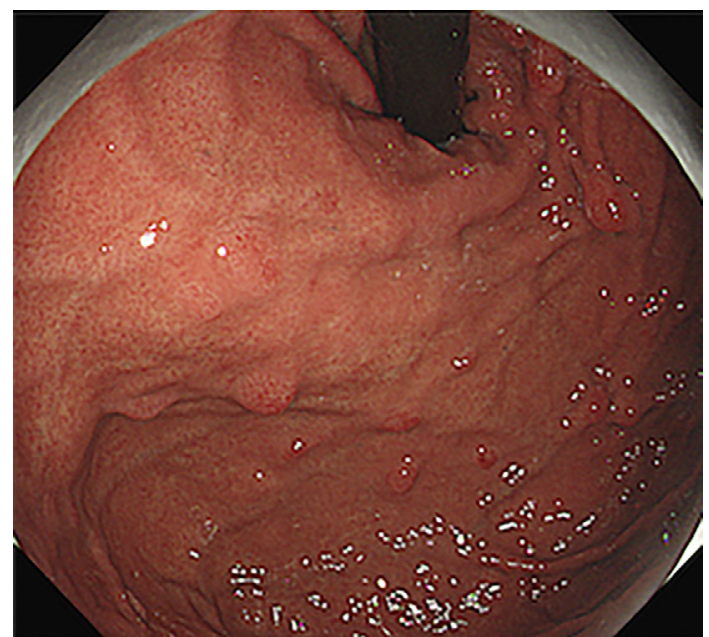

Figure 5. Endoscopic image 1 year after the cessation of proton pump inhibitor treatment. Note the near-complete disappearance of gastric hyperplastic polyps.

\section{References}

1. Haastrup PF, Paulsen MS, Christensen RD, Sondergaard J, Hansen JM, Jarbol DE. Medical and non-medical predictors of initiating long-term use of proton pump inhibitors: a nationwide cohort study of first-time users during a 10-year period. Aliment Pharmacol Ther 44: 78-87, 2016.

2. Boutet R, Wilcock M, MacKenzie I. Survey on repeat prescribing for acid suppression drugs in primary care in Cornwall and the Isles of Scilly. Aliment Pharmacol Ther 13: 813-817, 1999.

3. Corley DA, Kubo A, Zhao W, Quesenberry C. Proton pump inhibitors and histamine-2 receptor antagonists are associated with hip fractures among at-risk patients. Gastroenterology 139: 93101, 2010.

4. Leonard J, Marshall JK, Moayyedi P. Systematic review of the risk of enteric infection in patients taking acid suppression. Am J Gastroenterol 102: 2047-2056, 2007.
5. Hongo M, Fujimoto K; Gastric Polyps Study Group. Incidence and risk factor of fundic gland polyp and hyperplastic polyp in long-term proton pump inhibitor therapy: a prospective study in Japan. J Gastroenterol 45: 618-624, 2010.

6. Kumar KR, Iqbal R, Coss E, Park C, Cryer B, Genta RM. Helicobacter gastritis induces changes in the oxyntic mucosa indistinguishable from the effects of proton pump inhibitors. Hum Pathol 44: 2706-2710, 2013.

7. Jalving M, Koornstra JJ, Wesseling J, Boezen HM, DE Jong S, Kleibeuker JH. Increased risk of fundic gland polyps during longterm proton pump inhibitor therapy. Aliment Pharmacol Ther 24: 1341-1348, 2006.

8. Graham JR. Gastric polyposis: onset during long-term therapy with omeprazole. Med J Aust 157: 287-288, 1992.

9. Stolte M, Sticht T, Eidt S, Ebert D, Finkenzeller G. Frequency, location, and age and sex distribution of various types of gastric polyp. Endoscopy 26: 659-665, 1994.

10. Borch K, Skarsgard J, Franzen L, Mardh S, Rehfeld JF. Benign gastric polyps: morphological and functional origin. Dig Dis Sci 48: 1292-1297, 2003.

11. Elhanafi S, Saadi M, Lou W, et al. Gastric polyps: Association with Helicobacter pylori status and the pathology of the surrounding mucosa, a cross sectional study. World J Gastrointest Endosc 7: 995-1002, 2015.

12. Ji F, Wang ZW, Ning JW, Wang QY, Chen JY, Li YM. Effect of drug treatment on hyperplastic gastric polyps infected with Helicobacter pylori: a randomized, controlled trial. World J Gastroenterol 12: 1770-1773, 2006.

13. Tokunaga K, Tanaka A, Takahashi S. [Gastric hyperplastic polyps and $H$. pylori infection, their relationship and effects of eradication therapy]. Nihon Rinsho 71: 1449-1452, 2013 (in Japanese, Abstract in English).

14. Jain R, Chetty R. Gastric hyperplastic polyps: a review. Dig Dis Sci 54: 1839-1846, 2009.

15. Kato M. Endoscopic findings of $H$. pylori infection. In: Helicobacter pylori. Suzuki H, Warren R, Marshall B, Eds. Springer, Japan, 2016: 157-167.

16. Parks T, Ragland KL, Steiner MA, Subramony C, Bishop P, Nowicki M. Ménétrier mimicker complicating ulcerative colitis: proton-pump inhibitor-induced hyperplastic polyps. J Pediatr 167: 
$776 \mathrm{e} 1,2015$.

17. Alqutub AN, Masoodi I. A case of gastric polyposis in antral area of stomach following prolonged proton-pump therapy. Ger Med Sci 8: Doc 19, 2010.

18. Ito M, Tanaka S, Maeda M, et al. Role of the gastrin-gastrin receptor system in the expansive growth of human gastric neoplasms. Digestion 78: 163-170, 2008.

19. Carmack SW, Genta RM, Schuler CM, Saboorian MH. The current spectrum of gastric polyps: a 1-year national study of over 120,000 patients. Am J Gastroenterol 104: 1524-1532, 2009.

20. Ohkusa T, Takashimizu I, Fujiki K, et al. Disappearance of hyperplastic polyps in the stomach after eradication of Helicobacter pylori. A randomized, clinical trial. Ann Intern Med 129: 712-715, 1998.

21. Nam SY, Park BJ, Ryu KH, Nam JH. Effect of Helicobacter pylori infection and its eradication on the fate of gastric polyps. Eur J Gastroenterol Hepatol 28: 449-454, 2016.

22. Abraham SC, Singh VK, Yardley JH, Wu TT. Hyperplastic polyps of the stomach: associations with histologic patterns of gastritis and gastric atrophy. Am J Surg Pathol 25: 500-507, 2001.

23. Takamura A, Ito M, Boda T, et al. High expression of gastrin receptor protein in injured mucosa of Helicobacter pylori-positive gastritis. Dig Dis Sci 58: 634-640, 2013.

24. Tahara E. Growth factors and oncogenes in human gastrointestinal carcinomas. J Cancer Res Clin Oncol 116: 121-131, 1990.

25. Waldum HL, Brenna E. [Role of the enterochromaffin-like cells and histamine in the regulation of gastric acid secretion]. Gastroenterol Clin Biol 15: 65C-72C, 1991 (in French).
26. Sekikawa A, Fukui H, Fujii S, et al. REG Ialpha protein may function as a trophic and/or anti-apoptotic factor in the development of gastric cancer. Gastroenterology 128: 642-653, 2005.

27. Steele IA, Dimaline R, Pritchard DM, et al. Helicobacter and gastrin stimulate Reg1 expression in gastric epithelial cells through distinct promoter elements. Am J Physiol Gastrointest Liver Physiol 293: G347-G354, 2007.

28. Bhandari S, Bakke I, Kumar J, et al. Connective tissue growth factor is activated by gastrin and involved in gastrin-induced migration and invasion. Biochem Biophys Res Commun 475: 119-124, 2016.

29. Kazumori H, Ishihara $S$, Fukuda R, Kinoshita Y. Localization of Reg receptor in rat fundic mucosa. J Lab Clin Med 139: 101-108, 2002.

30. Mathieu N. [Risk of long-term treatment with proton pump inhibitors]. Rev Prat 58: 1451-1454, 2008 (in French, Abstract in English).

31. Orlowska J, Kupryjanczyk J. Malignant transformation of gastric hyperplastic polyps. Am J Clin Pathol 117: 165-166, 2002.

32. Ahn JY, Son da H, Choi KD, et al. Neoplasms arising in large gastric hyperplastic polyps: endoscopic and pathologic features. Gastrointest Endosc 80: 1005-1013, 2014.

The Internal Medicine is an Open Access article distributed under the Creative Commons Attribution-NonCommercial-NoDerivatives 4.0 International License. To view the details of this license, please visit (https://creativecommons.org/licenses/ by-nc-nd/4.0/).

(C) 2017 The Japanese Society of Internal Medicine http://www.naika.or.jp/imonline/index.html 